\title{
Absenteeism among nursing technicians from a regional refer- ence hospital in a countryside of northeastern Brazil
}

\author{
Francisco Rosemiro Guimarães Ximenes Neto ${ }^{1,2}$, Francisca Nelyana da Silva Sabino ${ }^{1}$, Maria Helena Machado², Luciano \\ Garcia Lourenção ${ }^{3}$, Francisco Diogenes dos Santos ${ }^{1,4}$, Layse Fernandes Queiroz Vasconcelos', Eliany Nazaré Oliveira ${ }^{1}$, \\ Antônio Ademar Moreira Fontenele Júnior", Neyson Pinheiro Freire ${ }^{5,6}$, Isabel Cristina Kowal Olm Cunha ${ }^{6}$, Tarciana \\ Ferreira-Serafim ${ }^{1}$, Betânia Maria Pereira dos Santos5,6,7, Antonio Marcos Freire Gomes 5,6 , Gilvan Brolini ${ }^{5,6}$, Jacqueline \\ Flores de Oliveira ${ }^{3}$, Natalia Sperli Geraldes Marin dos Santos Sasaki ${ }^{8}$, Maria de Lourdes Sperli Geraldes Santos ${ }^{8}$, Sidi- \\ ane Teixeira Rodrigues ${ }^{3}$, José Gustavo Monteiro Penhas³, Daniela Menezes Galvão³, Taisa Moitinho de Carvalho8
}

\footnotetext{
Health Sciences Center, Vale do Acaraú State University. Sobral, Ceará, Brazil

2 National School of Public Health, Oswaldo Cruz Foundation (FIOCRUZ). Rio de Janeiro, RJ, Brazil

3 Nursing School, Federal University of Rio Grande, Rio Grande, Rio Grande do Sul, Brazil

4 Federal University of Ceará, Sobral, CE, Brazil.

5 Federal Council of Nursing. Brasília, Federal District, Brazil

6 Paulista School of Nursing, Federal University of Sao Paulo. São Paulo, São Paulo, Brazil

7 Technical School of Health, Federal University of Paraíba. João Pessoa, Paraíba, Brazil

8 School of Medicine of São José do Rio Preto. São José do Rio Preto, São Paulo, Brazil

* Correspondence: rosemironeto@gmail.com
}

\begin{abstract}
This study aimed to identify the most relevant factors of absenteeism in the perception of nursing technicians from a regional reference hospital in Brazil. A cross-sectional study, based on a case study, was conducted from August 2018 to July 2021, with 324 nursing technicians from a Brazilian macroregional reference hospital in Northwestern Ceará. Data were collected through Google Forms ${ }^{\circledR}$ via the Scale of Factors of Work Absenteeism (EFAL). For data analysis, the overall mean and means of the four EFAL factors were calculated. The individuals were grouped by rating level and data were presented descriptively. The results showed that fatigue, low pay, work overload, need to resolve unpostponable personal/family bureaucratic matters, and need for time to continue/post-graduate education were the main causes of absenteeism. In general, nursing technicians' perceptions varied between low and medium relevance to the factors that contributed to work absenteeism. We can associate these results to the low frequency of absenteeism among the professionals of the institution.
\end{abstract}

Keywords: absenteeism; nursing; licensed practical nurses; nursing staff, hospital; occupational health.

\section{Introduction}

The work process has undergone several transformations as a consequence of globalization, leading to an intense productive restructuring. These transformations have had a significant impact on the health-disease-care process of workers. In a hospital setting, such changes result in new advances, causing modifications in the organization of daily practice [1].

A hospital, a complex institution with significant technological and cognitive density, provides various specialized care to its users according to their needs. The provision of care requires the attention and effective performance of professionals, as well as managers who value the development of qualified work [1].

In the entire Brazilian health system, nursing (composed of nursing auxiliaries, technicians, and nurses) constitutes the largest Workforce in Health (FTS). Auxiliaries and technicians perform less complex care actions, however, dedicate most of their time 
to direct and continuous care to the clientele. They are the front-line in many sectors, such as the emergency room, maternity, surgical center, Intensive Care Unit (ICU), and are exposed to several risks, diseases, and illnesses [2].

A hospital environment interferes significantly in the health-disease-health-care-work process of nursing, confined to the intense rhythms, multiple working hours, unhealthy environments, overload of services, low remuneration, subject to accidents, and physical, biological, chemical, psychological, and ergonomic risks, besides the visible professional devaluation [3]. A study showed that the work activities developed by these professionals significantly influenced the health-disease-care process, which brought both benefits and harms. The intense working hours and work pace is associated with stress caused by living with the suffering of clients and family members. Furthermore, the inadequacy of the resources made available by the institutions cause intense physical and mental exhaustion [4].

It is also a fact that the working conditions can influence absenteeism, causing overload and dissatisfaction in the team. Furthermore, absenteeism harms the quality of care provided to the clientele, causes physical and psychological stress, and favors illness in general $[5,6]$.

Conceptually, absenteeism is a term used to characterize the absence of a professional previously scheduled to work. In addition, there are numerous factors that influence it in a work environment. Thus, it is possible to classify absenteeism as: planned, related to scheduled absences, such as days off, vacations and maternity leave, and not planned, regarding non-programmed absences, such as medical certificates or suspension $[7,8]$.

In recent years, research on absenteeism has increased. However, limited studies have been directed to the nursing technicians category, despite them dedicating more time to the client and providing assistance through direct and continuous care, close to the bed. Therefore, this study focused on nursing technicians and aimed to identify the most relevant factors of absenteeism from their perspective in a regional reference hospital in Brazil.

\section{Materials and Methods}

\subsection{Type of Study}

This was a cross-sectional research, under a quantitative approach, based on a case study, conducted on nursing technicians from a Northern Regional Hospital (HRN) of Ceará (BR) from August 2018 to July 2021.

The HRN, an institution operating since 2013, is a state tertiary reference unit for 55 municipalities that make up the Health Macro-region of Sobral. It consisted of 410 beds (298 inpatient and 112 observation beds), distributed in the following services: Ambulatory, Surgical Center, Surgical Clinic, Medical Clinic, Adult Emergency, Pediatric Emergency, Obstetric Clinic, Pediatric Clinic, Neurosurgery, Neuroradiology, ICU - Adult, ICU - Pediatric, Neonatology, ICU - Neo, and Intermediate Care Unit (ICU) - Neo and Mother Kangaroo [9].

\subsection{Sample and Participants}

The HRN had a Health Workforce (HWF) of 1,595 permanent workers (contract governed by the Consolidation of Labor Laws) and 398 contracted by other modalities (cooperated, service contract, outsourced, and legal entity). Of these, 627 (39\%) were nursing technicians.

The nursing technicians of the HRN were selected as subjects since they represented the majority of the hospital FTS and performed most of the actions and provided direct care to the clients. Further, limited studies have been conducted on these professionals.

To calculate the maximum sample size, we adopted a percentage of reasonable working conditions of $50 \%$. A confidence level of $95 \%$ and a margin of error of $5 \%$ were set. A sample of 239 professionals was obtained. 
The inclusion criteria included nursing technicians who a) were in full exercise of their occupation and b) had worked in the institution for at least three months (minimum time to understand the work dynamics and routines of the institution). The exclusion criteria included those who a) held an administrative position and/or b) were on vacation or maternity or sick leave during the data collection period.

\subsection{Procedures, Measurements, Variables, and Outcome}

For data collection, an electronic questionnaire was administered via Google Forms ${ }^{\circledR}$. Initially, a pre-test was conducted with six nursing technicians from the institution itself. The identified inconsistencies were considered and the necessary arrangements were made to avoid further problems. Next, the questionnaire was sent to the professionals, through social networks and institutional WhatsApp ${ }^{\circledR}$ groups, to be answered on institutional computers or personal cell phones.

Despite our efforts, there was a low adherence of technicians, due to difficulties in handling the virtual tool and accessibility to the internet via this method. To increase the sample size, we opted for a printed questionnaire, distributed by the researchers in various sectors of the hospital. The workers could answer immediately or hand them in during their next shift. This strategy achieved positive results and consolidated data collection.

To evaluate the level of absenteeism among nursing technicians, we used the Scale of Factors of Work Absenteeism (EFAL), proposed by Jesus and Murcho [10] and validated in Brazil by Gomide Junior, Esteves, and Silva [11]. The EFAL was constructed and validated to evaluate the perception of workers regarding the factors of discomfort related with work absenteeism [10,11].

The scale consisted of 19 items and was divided into four factors: EFAL 1 - Interpersonal and work environment factors, which consisted of items 8, 11, 13, 14, 17, and 18; EFAL 2 - Psychosomatic and work conditions factors, which consisted of items 3, 5, 9, 12, and 19; EFAL 3 - Administrative-labor factors, which consisted of items 1, 2, 4, and 6; and EFAL 4 - Time and career management factors, which consisted of items 7, 10, 15, and 16.

All the items had a negative connotation. Since the EFAL was intended for individual application, it was important that the participants understood the instructions and how to mark their answers. It should be certified that the environment of the application of the instrument was comfortable and quiet, and there was no time limit [10].

To calculate the overall score of the EFAL, all the items were summed and divided by 19 . The average score of the scale factors were calculated from the sum of the items that composed each factor, divided by the number of items of each one, being: EFAL 1 sum of items 8, 11, 13, 14, 17 and 18 divided by six; EFAL 2 - sum of items 3, 5, 9, 12 and 19 divided by five; EFAL 3 - sum of items 1, 2, 4 and 6 divided by four; EFAL 4 - sum of items 7, 10, 15 and 16 divided by four [10].

\subsection{Statistical Analysis}

The data were stored in a Microsoft Excel® spreadsheet, which allowed the identification and exclusion of incomplete questionnaires. Then, the overall mean score and the mean scores for each factor of the EFAL scale were calculated for each participant. The values of the scores ranged from one to six. For their interpretation it was considered that the higher the value of the average score, the greater the perception of importance the professional gave to the factor of discomfort related with work absenteeism [10].

Therefore, scores with values $\geq 1$ and $\leq 2,>2$ and $\leq 4$, and $>4$ and $\leq 6$ indicated little, medium, and a high level of importance/relevance in the worker's perception, respectively [10].

\subsection{Ethical Considerations}

This study was approved by the institutional ethics committee (decision: 2,989,786 October 30, 2018; CAAE: 01157218.0.0000.5053). All the participants were only included after informed consent was obtained. All procedures performed were compatible with 
the ethical standards of the institutional research committee and with those of the Declaration of Helsinki and its comparable ethical standards.

\section{Results}

The study included 284 nursing technicians from a Northern Regional Hospital of Ceará. The participants were predominantly female (66.9\%), aged between 19 to 39 years $(84.5 \%)$, Hispanic $(67.6 \%)$, single $(46.1 \%)$ or married/consensual union $(46.1 \%)$ (Table 1$)$.

Table 1. Sociodemographic characteristics of the nursing technicians. North Regional Hospital, Ceará, Brazil.

\begin{tabular}{lc}
\hline \multicolumn{1}{c}{ Variables } & $\mathbf{n}(\mathbf{\%})$ \\
\hline Sex & \\
Male & $190(66.9)$ \\
Female & $93(32.7)$ \\
No answer & $01(0.4)$ \\
Age Group (years) & \\
19 to 29 & $128(45.1)$ \\
30 to 39 & $112(39.4)$ \\
40 to 49 & $31(10.9)$ \\
$50+$ & $12(4.2)$ \\
No answer & $01(0.4)$ \\
Race & \\
Hispanics & $192(67.6)$ \\
Caucasians & $53(18.7)$ \\
Africans & $28(9.9)$ \\
Asians & $08(2.8)$ \\
Indigenous & $02(0.7)$ \\
No answer & $131(46.1)$ \\
Sivil Status & $01(0.4)$ \\
Married/Consensual Union & \\
Divorced/Divorced/Separated & $01(0.4)$ \\
Widower & \\
\hline & \\
No answer & $0.4)$ \\
\hline
\end{tabular}

An overall analysis of the workers' perceptions of the factors related with work absenteeism (Table 2) showed that interpersonal and work environment (EFAL 1) had the least influence on hospital absenteeism (score $=1.72$ ). Conversely, psychosomatic and working conditions (EFAL 2) had the most influence (score = 2.14).

Table 2. Scores from the Occupational Absenteeism Factors Scale for nursing technicians.

\begin{tabular}{ccc}
\hline Factors & Mean Score & $\begin{array}{c}\text { p-value } \\
\text { (t-test) }\end{array}$ \\
\hline EFAL 1 & 1.72 & \\
EFAL 2 & 2.14 & $<0.001$ \\
EFAL 3 & 2.11 &
\end{tabular}


An analysis of the values of the scores obtained by each professional for the work absenteeism factors are presented in Table 3. The results showed that $58.1 \%, 35.6 \%$, and $6.3 \%$ of the nursing technicians considered that the factors indicated in the instrument had little, medium, and high importance for absenteeism in the institution, respectively.

Regarding interpersonal and work environment factors associated with work absenteeism (EFAL 1), it was observed that $68.3 \%, 27.5 \%$, and $4.2 \%$ of the professionals considered that these had little, medium, and high importance/relevance for absenteeism, respectively.

Regarding psychosomatic and working conditions factors (EFAL 2), 51.1\%, 40.5\%, and $8.4 \%$ of the participants considered that these factors had little, medium, and high relevance for work absenteeism.

Regarding administrative-labor factors (EFAL 3), 51.8\%, 40.5\%, and 7.7\% considered that these factors had little, medium, and high relevance for work absenteeism.

Regarding time and career management factors (EFAL 4), 52.1\%, 39.1\%, and 8.8\% considered that these factors had little, medium, and high relevance for work absenteeism.

Table 3. Distribution of the nursing technicians according to individual mean scores.

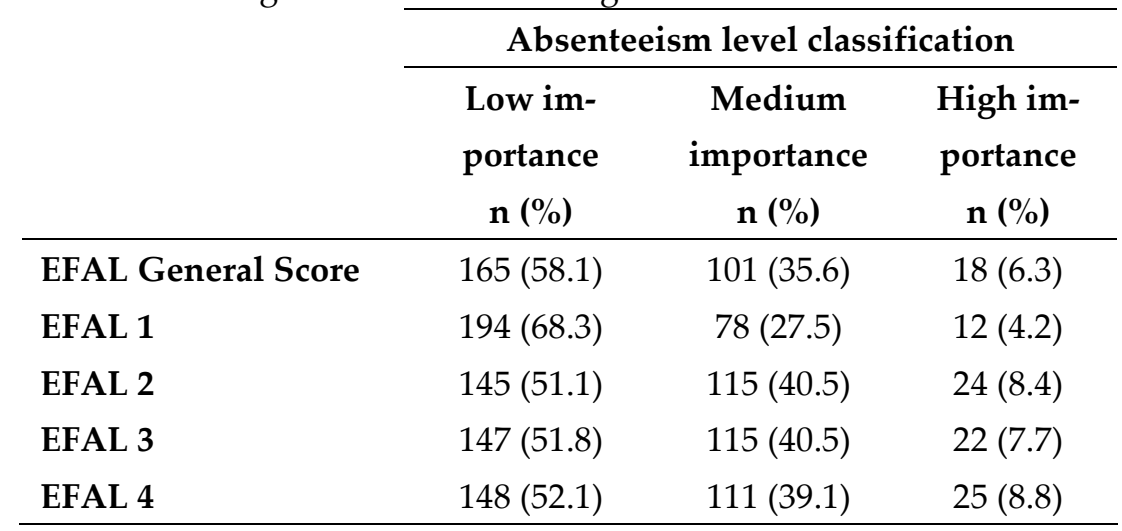

As shown in Table 4 , the most influential variables for work absenteeism were fatigue $(X=2.63)$, low pay $(X=2.48)$, work overload $(X=2.39)$, need to solve personal/family unpostponable bureaucratic matters $(X=2.38)$, need for time to continue/post-graduate education $(X=2.30)$, lack of professional recognition $(X=2.20)$, stress and anxiety $(X=2.19)$, and demotivation $(X=2.03)$.

Table 4. Mean scores of the EFAL items according to the evaluation of nursing technicians.

\begin{tabular}{lc}
\hline \multicolumn{1}{c}{ EFAL Items } & Mean Score \\
\hline 5. Tiredness & 2.63 \\
6. Low pay & 2.48 \\
9. Work overload & 2.39 \\
$\begin{array}{l}\text { 10. Need to resolve unpostponable personal/family bureaucratic matters (fi- } \\
\text { nances. banks. school etc.) }\end{array}$ & 2.38 \\
7. Need for time for continuing education/post-graduate training & 2.30 \\
2. Lack of professional recognition by $\quad$ others (other professionals. cli- & 2.20 \\
ents/patients etc.) & \\
3. Stress and anxiety & 2.19 \\
18. Demotivation & 2.03 \\
\hline
\end{tabular}


4. Feeling unjustified in the service/institution where he works

16. Feeling that he has stagnated in his career

15. Performing leisure activities that can't be done during vacations or vacations

19. Poor physical working conditions

Dissatisfaction with the organization of services

8. Problems with colleagues

17. Bad work environment

12. Shift work

14. Job instability

13. Not liking the functions performed

\section{Discussion}

In Brazil, the nursing team, composed of upper-level professionals (nurses) and mid-level professionals (nursing technicians and assistants), represents the largest FTS in the country. According to data from the Federal Council of Nursing, nursing technicians correspond to $61.2 \%$ of these workers, being the largest category of professionals in the Macro Health Sector (1,686,954 professionals) [12].

Nursing technicians provide care at various levels of the healthcare system, from Primary Health Care (PHC) to urgent and emergency care, mobile health services, and medium- and high-complexity hospital units [13]. In these diverse work environments, adequate work conditions, such as appropriate environment, good physical structure, and the availability of equipment and quality materials, positively influence the work process and the quality of care provided. Conversely, inadequate work conditions, such as unhealthy and disorganized environments, lack of supplies, low-quality equipment, work overload, professional devaluation, lack of support for professional improvement, and low salaries, contribute to the process of ill health and increased risk of absenteeism $[7,14]$.

In a hospital environment, nursing technicians provide direct and continuous care, by performing procedures under their responsibility and spending most of the time in contact with the client at their bedside [15]. This work routine exposes them to physical, biological, and chemical risks, as well as work accidents, which influences emotional suffering, reduces their quality of life, affects the health-disease process [16], and contributes to the increase of absenteeism, as evidenced in our study. This indicated that psychosomatic and working conditions were factors that significantly influenced work absenteeism of nursing technicians in the hospital environment.

In our study, although most professionals had the perception that the factors indicated in EFAL had little influence on absenteeism, we noticed that there was an important percentage who considered that these factors had great relevance in favoring absenteeism in the institution, especially time and career management factors (8.8\%), psychosomatic and working conditions factors $(8.4 \%)$, and administrative-labor factors $(7.7 \%)$. These results show that the work process of nursing technicians can favor absenteeism in the nursing team, and represents a complex problem since the absence of professionals interferes with the dynamics of work in health institutions and is related with occupational diseases [17].

Some variables, such as fatigue, low pay, work overload, the need to solve personal/family unpostponable bureaucratic issues, need for time to continue education, lack of professional recognition, stress, anxiety, and demotivation, were indicated as most influential factors for work absenteeism, which corroborated with previous literature. 
Studies showed evidence that professionals who had long working hours, exhausting routines, fast pace, reduced rest periods, and inappropriate wages, had higher chances of leaving the workplace, due to illness, physical fatigue, psychological stress, anxiety, and depression [18-20].

These factors are strongly related to an increasingly competitive labor market, with low wages and appreciation and high expectation in the labor market, generating a dangerous work overload with a double or triple work day [21,22].

A hospital environment is considered the most stressful of all health establishments, with an intense work routine, in which professionals witness the suffering of the sick. These factors can cause a significant increase in work stress, compromising the quality of life and triggering the workers' illness, leading to a loss in the quality of care $[8,16,17,23]$.

Routine, mechanical, and repetitive work can cause physical and psychological stress for workers which can lead to a reduction or loss of work capacity. Furthermore, it can compromise their health, favor the appearance of musculoskeletal diseases and other labor-related illnesses, and often lead to absenteeism [24,25]. When workers go off work due to an illness, they generate an overload of work for others, which contributes to work stress, physical fatigue, and psychological stress and favors the absence of more workers $[14,27]$.

There was a higher probability of absences related with illness among professionals who occupied a lower hierarchical level, which confirmed the high influence of the lack of professional recognition for absenteeism, as observed in our study. Corroborating these results, a Brazilian study on absenteeism due to illness among nursing professionals indicated that, in a work environment, nursing technicians withdrew more from their work activities compared to nurses [28].

In South Africa, a study identified the relationship between absenteeism and the qualified work environment and verified that professionals who worked in environments favorable to the development of their work activities were less likely to be absent compared to professionals who performed their practices in unhealthy places favorable to physical and psychological stress [29].

One of the greatest causes of psychological problems among the nursing team, especially technicians, is the emotional control. The assistance through direct and continuous contact with the patient makes mid-level professionals share the pain, anguish, and suffering of their clients and family members. Despite being moved, they cannot show discomfort or weakness. This accumulation compromises their psychological and social health and contributes to illness [18]. Similarly, a lack of a good interpersonal relationship can cause stress at work and favor absenteeism [7].

The importance of the work of healthcare institution managers in the identification and control of absences among nursing workers is highlighted. People management indicators, such as turnover and absenteeism, evaluate the quality of the care provided. When high, they overburden the other professionals, interfere in care, reduce the effectiveness of work, generate physical and psychological wear of workers, and favor illness, in addition to impairing the engagement at work and the worker's commitment to the career [26,30-35].

Thus, the environment and work management significantly influences the general well-being of professionals and affects their performance. Poor leadership practices by managers, characterized by a lack of autonomy and responsibility with the servers, absence of communication, professional devaluation, hierarchies, among other factors, interfere negatively in the organization of work, compromises the provision of care, causes stress, affects the health of the workers, and generates conflicts among the team [36].

As identified in this study, several factors had a relevant influence on the absenteeism of nursing technicians (scores $>2$ ), which confirmed that absenteeism had multifactorial causes and was closely related with the professionals' working environment and conditions $[36,38]$. It is common that low salaries force these professionals to have more than one work bond, which generates long and tiring working hours. Such factors lead to 
physical and psychological fatigue, which affects their performance, contributes to the appearance of health problems, and increases the risk of work absenteeism $[21,39,40]$.

This study design does not allow the establishment of cause and effect relationships. However, our results should be carefully appreciated since they present a diagnosis of the reality of nursing technicians in a pre-pandemic period. Considering the significant impact of the COVID-19 pandemic on the mental health of healthcare workers [23,41-43], we highlight the need for research on work absenteeism among nursing staff during the pandemic period.

\section{Conclusions}

The most relevant factors of absenteeism in the perception of nursing technicians were fatigue, low pay, work overload, need to solve personal/family bureaucratic issues that could be postponed, and need for time to continue education/post-graduation. In general, their perceptions varied between low and medium relevance to the factors that contributed to work absenteeism. We can associate these results to the low frequency of absenteeism among the professionals in the institution.

The results of this study can support future research related with the perception of nursing professionals regarding the relevant factors for work absenteeism regarding the COVID-19 pandemic, which had a significant impact on the physical and mental health of health professionals worldwide.

Author Contributions: Conceptualization, F.R.G.X.N; F.N.S.S. and M.H.M.; methodology, F.R.G.X.N. and F.N.S.S.; software, F.R.G.X.N.; validation, F.R.G.X.N.; F.N.S.S.; M.H.M.; L.G.L.; F.D.S.; L.F.Q.V.; E.N.O.; A.A.M.F.J.; N.P.F.; I.C.K.O.C.; T.F.S.; B.M.P.S.; A.M.F.G.; G.B.; J.F.O.; N.S.G.M.S.S.; M.L.S.G.S.; S.T.R.; J.G.M.P.; D.M.G.; and T.M.C.; formal analysis, F.R.G.X.N. and L.G.L.; investigation, F.R.G.X.N. and F.N.S.S.; resources, .R.G.X.N; F.N.S.S. and M.H.M.; data curation, F.R.G.X.N.; writing - original draft preparation, F.R.G.X.N.; F.N.S.S. and M.H.M.; writing-review and editing, L.G.L.; F.D.S.; L.F.Q.V.; E.N.O.; A.A.M.F.J.; N.P.F.; I.C.K.O.C.; T.F.S.; B.M.P.S.; A.M.F.G.; G.B.; J.F.O.; N.S.G.M.S.S.; M.L.S.G.S.; S.T.R.; J.G.M.P.; D.M.G. and T.M.C.; visualization, F.R.G.X.N.; F.N.S.S.; M.H.M.; L.G.L.; F.D.S.; L.F.Q.V.; E.N.O.; A.A.M.F.J.; N.P.F.; I.C.K.O.C.; T.F.S.; B.M.P.S.; A.M.F.G.; G.B.; J.F.O.; N.S.G.M.S.S.; M.L.S.G.S.; S.T.R.; J.G.M.P.; D.M.G. and T.M.C.; supervision, F.R.G.X.N.; project administration, F.R.G.X.N. All authors have read and agreed to the published version of the manuscript.

Funding: This research received no external funding.

Institutional Review Board Statement: The study was conducted according to the guidelines of the Declaration of Helsinki. The study was approved by the Research Ethics Committee at Vale do Acaraú State University (decision: 2,989,786; CAAE: 01157218.0.0000.5053) on October 30, 2018.

Informed Consent Statement: Informed consent was obtained from all the subjects involved in the study.

Data Availability Statement: The datasets generated during the current study are not publicly available but are available from the corresponding author on reasonable request.

Conflicts of Interest: The authors declare no conflicts of interest.

\section{References}

1. Leal, L.A.; Henriques, S.H.; Brito, L.J.S.; Celestino, L.C.; Ignácio, D.S.; Silva, A.T. Health care models and their relationship with hospital nursing management. Rev enferm UERJ 2019, 27, e43769.

http://dx.doi.org/10.12957/reuerj.2019.43769

2. Souza, L.M.; Davila, E.S.; Scopel, C.D.; Barbieri, P.N.A. Absenteísmo e sintomas osteomusculares em técnicos e auxiliares de enfermagem de unidades de internação hospitalar. Rev Enferm UFSM 2018, 8, 366-379. http://dx.doi.org/10.5902/2179769228685 
3. Azevedo, J.N.L.; Silva, R.F.; Macêdo, T.T.S. Principais causas de absenteísmo na equipe de enfermagem: revisão bibliográfica. Rev Enferm Contemp 2019, 8, 80-86. http://dx.doi.org/10.17267/2317-3378rec.v8i1.1611

4. Silva, K.G.; Medeiros, C.R.S.; Soares, S.S.S.; Santos, D.C.A.; Souza, N.V.D.O.; Farias, S.N.P. Association between sociodemographic characteristics and quality of life domains in nursing professionals. Rev Rene 2020, 21, e43453. https://doi.org/10.15253/2175-6783.20202143453

5. Heylmann, N.R.; Nunes, J.F.S.; Fermino, N.; Ascari, R.A. Absenteísmo entre profissionais de enfermagem: estudo num Hospital Universitário Catarinense. Uningá Review J 2016, 26, 10-15. Available online: http://revista.uninga.br/index.php/uningareviews/article/view/1801 (accessed on 20 Jan 2022).

6. Julio, R.S.; Lourenção, L.G.; Penha, J.G.M.; Oliveira, A.M.N.; Nascimento, V.F.; Oliveira, S.M.; Gazetta, C.E. Anxiety, depression, and work engagement in Primary Health Care nursing professionals. Rev Rene 2021, 22 , e70762. http://dx.doi.org/10.15253/2175-6783.20212270762

7. Ferro, D.; Zacharias, F.C.; Fabriz, L.A.; Schonholzer, T.E.; Valente, S.H.; Barbosa, S.M.; Viola, C.G.; Pinto, I.C. Absenteeism in the nursing team in emergency services: implications in care. Acta Paul Enferm 2018, 31, 399-408. https://doi.org/10.1590/1982-0194201800056

8. Moreira, L.R.; Gomes, I.C.S.; Toledo, J.F.C.; Vieira, L.F.; Nascimento, R.S. Fatores que interferem no absenteísmo de técnicos de enfermagem em unidade de pronto atendimento hospitalar. Percurso Acad 2019, 9, 57-70. https://doi.org/10.5752/P.2236-0603.2019v9n18p57-70

9. Instituto de Saúde e Gestão Hospitalar (BR). Hospital Regional Norte (HRN). Available online: https://www.isgh.org.br/hospital-regional-norte (accessed on 20 Jan 2022).

10. Jesus, S.N.; Murcho, N.A. Absenteísmo no trabalho. In Novas Medidas do Comportamento Organizacional - Ferramentas de Diagnóstico e de Gestão. 1st ed.; Siqueira, M.M., Ed.; Artmed: Porto Alegre, Brasil, 2014 ; pp. 15-24.

11. Gomide Junior, S.; Esteves, M.A.S.; Silva, L.C.O. Adaptação e Validação Transcultural de uma Medida de Fatores de Absenteísmo. Psico-USF 2020, 25, 357-369. https://doi.org/10.1590/1413-82712020250213

12. Conselho Federal de Enfermagem (BR). Enfermagem em números. COFEN, 2019. Available online: http://www.cofen.gov.br/enfermagem-em-numeros (accessed on 15 Jan 2022).

13. Silva, M.C.N.; Machado, M.H. Health and Work System: challenges for the Nursing in Brazil. Ciênc. Saúde Colet 2020, 25, 7-13. https://doi.org/10.1590/1413-81232020251.27572019

14. Brey, C.; Miranda, F.M.D.; Haeffner, R.; Castro, I.R.S.; Sarquis, L.M.M.; Felli, V.E. O Absenteísmo entre os Trabalhadores de Saúde de um Hospital Público do Sul do Brasil. Rev. enferm. Cent.-Oeste Min 2017,7, e1135. http://dx.doi.org/10.19175/recom.v7i0.1135

15. Sousa, M.M.; Neiva, M.J.L.M.; Silva, M.F.N.; Vieira, J.L.; Melo, M.F.; Reis, E.M.; Ferreira, M.A.L.; Rocha, L.R. Cuidados de enfermagem na prevenção às lesões por pressão em pacientes hospitalizados. Braz. J. Hea. Rev 2019, 5, 4336-4344. https://doi.org/10.34119/bjhrv2n5-036

16. Santos, S.V.M.; Macedo, F.R.M.; Resck, Z.M.R.; Sanches, R.S.; Nogueira, D.A.; Terra, F.S. Características Socioeconômicas, Epidemiológicas e Laborais de Profissionais de Enfermagem Hospitalar. Rev. enferm. Cent.-Oeste Min 2017, 7, e1391. http://dx.doi.org/10.19175/recom.v7i0.1391

17. Oliveira, P.B.; Coca, L.N.; Spiri, W.C. Absenteísmo e ambiente de trabalho. Esc Anna Nery 2021, 25, e20200223. https://doi.org/10.1590/2177-9465-EAN-2020-0223

18. Pinto, I.C.; Figueira, B.P.G.; Ferro, D.; Zacharias, F.C.M.; Gomide, M.F.S.; Arcêncio, R.A. Absenteeism and its implications for nursing care in emergency services. Rev. eletrônica enferm 2017, 19, a19. http://dx.doi.org/10.5216/ree.v19.40332

19. Rotta, D.S.; Pinto, M.H.; Lourenção, L.G.; Teixeira, P.R.; Gonsalez, E.G.; Gazetta, C.E. Anxiety and depression levels among multidisciplinary health residents. Rev Rene 2016, 17, 372-377. http://dx.doi.org/10.15253/2175-6783.2016000300010 
20. Fernandes, M.A.; Soares, L.M.D.; Silva, J.S. Work-related mental disorders among nursing professionals: a Brazilian integrative review. Rev. bras. med. trab 2018, 16, 218-224. https://doi.org/10.5327/Z1679443520180228

21. Soares, S.S.S.; Lisboa, M.T.L.; Queiroz, A.B.A.; Silva, K.G.; Leite, J.C.R.A.P.; Souza, N.V.D.O. Double working hours in nursing: difficulties faced in the labor market and daily work. Esc Anna Nery 2021, 25, e20200380. https://doi.org/10.1590/2177-9465-EAN-2020-0380

22. Leão, L.O.S. Organização do trabalho e transtornos mentais comuns nos técnicos de enfermagem de um hospital público universitário de grande porte. Master's Thesis, Federal University of Uberlândia, Uberlândia, MG, Brazil, 2018. http://dx.doi.org/10.14393/ufu.di.2018.85

23. Machado MH. Pesquisa Condições de Trabalho dos Profissionais de Saúde no Contexto da COVID-19 no Brasil. Relatório preliminar 2020/2021. Available online: http://informe.ensp.fiocruz.br/noticias/51044 (accessed on 15 Jan 2022).

24. Scherer, M.D.A.; Oliveira, N.A.; Pires, D.E.P.; Trindade, L.L.; Gonçalves, A.S.R.; Vieira, M. Aumento das cargas de trabalho em técnicos de enfermagem na Atenção Primária à Saúde no Brasil. Trab. Educ. Saúde 2016, 14, 89-104. https://doi.org/10.1590/1981-7746-sol00030

25. Cordioli, D.F.C.; Cordioli Junior, J.R.; Gazzeta, C.E.; Silva, A.G.; Lourenção, L.G. Occupational stress and work engagement in primary health care workers. Rev Bras Enferm 2019, 72, 1580-1587. http://dx.doi.org/10.1590/0034-7167-2018-0681

26. Cordioli Junior, J.R.; Cordioli, D.F.C.; Gazetta, C.E.; Silva, A.G.; Lourenção, L.G. Quality of life and osteomuscular symptoms in workers of primary health care. Rev Bras Enferm 2020, 73, e20190054. http://dx.doi.org/10.1590/0034-7167-2019-0054

27. Julio, R.S.; Lourenção, L.G.; Oliveira, S.M.; Farias, D.H.R.; Gazetta, C.E. Prevalence of anxiety and depression in Brazilian Primary Health Care workers. Cad. Bras. Ter. Ocup. 2022, 30 , e2997. https://doi.org/10.1590/2526-8910.ctoAO22712997

28. Mantovani, V.M.; Nazareth, J.K.; Keretzky, K.B.; Maciel, D.N.P.; Biasibetti, C.; Lucena, A.F.; Echer, I.C. Research absenteeism due to illness among nursing professionals. Rev Min Enferm 2015, 19, 641-646. http://dx.doi.org/10.5935/1415-2762.20150049

29. Mudaly, P.; Nkosi, Z.Z. Factors influencing nurse absenteeism in a general hospital in Durban, South Africa. J. Nurs. Manag 2015, 23, 623-631. https://doi.org/10.1111/jonm.12189

30. Feldhaus, C.; Santos, B.S.; Nishiyama, J.A.P.; Valim, M.D.; Tonini, N.S.; Oliveira, J.L.C. Absenteísmo na equipe de enfermagem intensivista: contribuições da literatura brasileira. Rev. Adm. Saúde (On-line) 2020, 20 , e248. https://dx.doi.org/10.23973/ras.80.248

31. Silva, A.G.; Cabrera, E.M.S.; Gazetta, C.E.; Sodré, P.C.; Castro, J.R.; Cordioli Jr, J.R.; Cordioli, D.F.C.; Lourenção, L.G. Engagement in primary health care nurses: A cross-sectional study in a Brazilian city. Public Health Nurs 2020, 37, 169-177. http://dx.doi.org/10.1111/phn.12694

32. Lima, M.P.; Costa, V.M.F.; Lopes, L.F.D.; Balsan, L.A.G.; Santos, A.S.; Tomazzoni, G.C. Levels of career commitment and career entrenchment of nurses from public and private hospitals. Rev. Lat.-Am. Enferm 2015, 23, 1033-40. https://doi.org/10.1590/0104-1169.0211.2646

33. Lourenção, L.G.; Oliveira, J.F.; Ximenes Neto, F.R.; Cunha, C.L.F.; Valenzuela-Suazo, S.V.; Borges, M.A.; Gazetta, C.E. Career commitment and career entrenchment among Primary Health Care workers. Rev Bras Enferm 2022, 75, e20210144. http://dx.doi.org/10.1590/0034-7167-2021-0144

34. Lourenção, L.G.; Silva, R.A.S.; Moretti, M.S.R.; Sasaki, N.S.G.M.S.; Sodré, P.C.; Gazetta, C.E. Career commitment and entrenchment among Primary Care nurses. Rev. esc. enferm. USP 2021, 55, e20210186. https://doi.org/10.1590/1980-220X-REEUSP-2021-0186

35. Lourenção, L.G. Work engagement among participants of residency and professional development programs in nursing. Rev Bras Enferm 2018, 71, 1487-1492. https://doi.org/10.1590/0034-7167-2017-0278 
36. Garcia, A.E.F.; Lemos, G.R.; Almeida, V.P.; Marta, C.B.; Machado, D.A. O custo do absenteísmo do profissional de enfermagem numa instituição pública. Enferm. Foco 2019, 10, 123-129. https://doi.org/10.21675/2357-707X.2019.v10.n5.2472

37. Luan, H.D.; Hai, N.T.; Xanh, P.T.; Giang, H.T.; Thuc, P.V.; Hong, N.M.; Khue, P.M. Musculoskeletal Disorders: Prevalence and Associated Factors among District Hospital Nurses in Haiphong, Vietnam. BioMed res. int 2018, 2018, 3162564. https://doi.org/10.1155/2018/3162564

38. Dyrbye, L.N.; Shanafelt, T.D.; Johnson, P.O.; Johnson, L.A.; Satele, D.; West, C.P. A cross-sectional study exploring the relationship between burnout, absenteeism, and job performance among American nurses. BMC Nurs $2019,18,57$. https://doi.org/10.1186/s12912-019-0382-7

39. Pimenta, C.J.L.; Bezerra, T.A.; Martins, K.P.; Costa, T.F.; Viana, L.R.C.; Costa, M.M.L.; Costa, K.N.F.M. Pleasure and suffering among hospital nurses. Rev Bras Enferm 2020, 73, e20180820. http://dx.doi.org/10.1590/0034-7167-2018-0820

40. Tracera, G.M.P.; Santos, K.M.; Nascimento, F.P.B.; Sousa, K.H.J.F.; Portela, L.F.; Zeitoune, R.C.G. Factors associated with absenteeism of nursing professionals in university outpatient clinics in Brazil. J. nurs. manag 2020, 28, 1259-1267. https://doi.org/10.1111/jonm.13073

41. Muller, A.E.; Hafstad, E.V.; Himmels, J.P.W; Smedslund, G.; Flottorp, S.; Stensland, S.O.; Stroobants, S.; Velde, S.V.; Vist, G.E. The mental health impact of the covid-19 pandemic on healthcare workers, and interventions to help them: A rapid systematic review. Psychiatry res 2020, 293, 113441. https://doi.org/10.1016/j.psychres.2020.113441

42. Vizheh, M.; Qorbani, M.; Arzaghi, S.M.; Muhidin, S.; Javanmard, Z.; Esmaeili, M. The mental health of healthcare workers in the COVID-19 pandemic: A systematic review. J Diabetes Metab Disord 2020, 19, 1967-1978. https://doi.org/10.1007/s40200-020-00643-9

43. Spoorthy, M.S.; Pratapa, S.K.; Mahant, S. Mental health problems faced by healthcare workers due to the COVID-19 pandemic - a review. Asian journal of psychiatry 2020, 51, 102119. https://doi.org/10.1016/j.ajp.2020.102119 